09

\title{
Возможности двухфотонной конфокальной микроскопии для исследования объемных характеристик полупроводниковых материалов
}

\author{
(C) В.П. Калинушкин, О.В. Уваров
}

Институт общей фризики им. А.М. Прохорова РАН, 119991 Москва, Россия

e-mail: vkalin@kapella.gpi.ru

(Поступило в Редакцию 11 декабря 2015 г.)

На примере кристаллов $\mathrm{Zn}-\mathrm{Se}$ рассматриваются перспективы использования двухфотонной конфокальной микроскопии для создания „плоских“ и „объемных карт“ межзонной и примесной люминесценции в полупроводниковых материалах. Показана возможность формирования таких „карт“ с шагом по глубине и пространственным разрешением по плоскости в несколько $\mu \mathrm{m}$ до расстояний от поверхности до $1 \mathrm{~mm}$. С помощью этой методики выявлены люминесцентно-активные неоднородности в кристаллах и исследованы их структуры и люминесцентные характеристики. Обсуждены перспективы использования двухфотонной конфокальной микроскопии для исследования других прямозонных полупроводников и материалов 4-й группы.

\section{Введение}

Исследование объемных характеристик полупроводниковых материалов является достаточно сложной и важной задачей. Так, одним из основных методов исследования полупроводников является изучение люминесценции, вызванной рекомбинацией неравновесных носителей. При этом для возбуждения неравновесных носителей часто используется излучение с энергией кванта больше ширины запрещенной зоны. Это излучение поглощается в узкой приповерхностной области кристалла толщиной обычно не более нескольких $\mu \mathrm{m}$. Соответственно исследуется люминесценция из этой области, которая несколько расширяется за счет диффузии неравновесных носителей. Полученные результаты в дальнейшем распространяются на весь объем. Очевидно, что это не совсем корректная процедура. Ясно, что свойства поверхности существенно отличаются от объемных. Хорошо известно, что результаты экспериментов по исследованию люминесценции с поверхностным возбуждением носителей сильно зависят от процедуры подготовки поверхности исследуемого образца. Также известно, что достаточно часто отличаются результаты исследования одних и тех же образцов при использовании поверхностной и объемной генерации носителей (например, [1-3]). Отдельной проблемой является исследование заведомо неоднородных материалов, получаемых, например, в результате термодиффузии легирующей примеси с поверхности образца. Другой важной задачей является исследование различных крупномасштабных дефектов (например, границ зерен в поликристаллических материалах) и их характеристик, которые с большой долей вероятности отличаются от средних объемных.

Таким образом, разработка методов, позволяющих исследовать объемные характеристики полупроводни- ковых кристаллов и создавать объемные карты этих характеристик с достаточно высоким пространственным разрешением, востребована. В настоящей работе рассматриваются возможности использования для этих целей двухфотонной конфокальной микроскопии.

\section{Методика эксперимента}

В настоящей работе использовались конфокальные микроскопы фирмы Carl Zeiss LSM 710 NLO. Подробно методика конфокальной микроскопии описана, например, в [4-6]. В настоящей работе регистрировалась люминесценция неравновесных носителей тока, генерируемых с помощью двухфотонного поглощения излучения лазеров, работающих в режиме гигантских импульсов. Такой метод возбуждения позволяет генерировать носители в объеме кристалла. Возможности конфокального микроскопа позволяют фокусировать излучение в небольшой объем (с размерами несколько $\mu \mathrm{m}$ ) и осуществлять сканирование областью возбуждения по всем трем координатам. Система детектирования люминесценции совмещается с областью возбуждения, что позволяет регистрировать люминесценцию именно из этой области. В настоящей работе система регистрации работала в режиме детектирования спектрального сигнала при мультифотонном возбуждении фемтосекундными импульсами ближнего ИК диапазона и поэтому пространственное разрешение определялось размером области возбуждения носителей. Эти возможности позволяют снимать „плоские“ и „объемные“ карты люминесценции с пространственным разрешением в несколько $\mu$ m. Кроме того, эти карты могут быть получены на разных спектральных интервалах люминесценции. Развитое математическое обеспечение, которым оснащены конфокальные микроскопы, позволяет производить анализ полученных результатов. 
Двухфотонное возбуждение осуществлялось лазером фирмы Coherent серии Chameleon с перестройкой длины волны в диапазоне $0.71-1.05 \mu \mathrm{m}$. Длительность импульса составляла $150 \mathrm{fs}$, частота $80 \mathrm{MGz}$. Максимальная средняя мощность была примерно $0.1-1 \mathrm{~W}$ и варьировалась в зависимости от условий детектирования и оптимизировалась для получения контрастного изображения люминесценции образца. Спектры люминесценции регистрировались в диапазоне $425-725 \mathrm{~nm}$ со спектральным разрешением $10 \mathrm{~nm}$. Эти параметры хорошо подходят для исследования кристаллов $\mathrm{Zn}-\mathrm{Se}$, ширина запрещенной зоны которых составляет примерно $2.7 \mathrm{eV}$. В результате имеется возможность осуществлять на указанных выше приборах двухфотонное возбуждении и регистрацию межзонной и, по крайней мере, части примесной люминесценции (в диапазоне $0.48-0.7 \mu \mathrm{m}$ ) этих кристаллов. Это позволило использовать данный материал для демонстрации возможностей двухфотонной конфокальной микроскопии для исследования объемных характеристик полупроводниковых материалов.

В принципе данный подход не нов, ранее сходная схема экспериментов предлагалась, например, в [7]. Новым в настоящей работе является демонстрация того, что возможности современных конфокальных микроскопов позволяют экспрессно получать огромные массивы информации об объемных характеристиках полупроводников и проводить их обработку.

В работе для демонстрации возможностей предлагаемой методики использовались поли- и монокристаллы $\mathrm{Zn}-\mathrm{Se}$, нелегированные и легированные железом. Поликристаллы синтезировались методом химического осаждения из газовой фазы. Монокристаллы $\mathrm{Zn}-\mathrm{Se}$ получены методом свободного роста на ориентированной в плоскости (111) подложке монокристаллического $\mathrm{ZnSe}$. Легирование железом проводилось с помощью термодиффузии. Концентрация железа у поверхности была высока - примерно $5 \cdot 10^{19} \mathrm{~cm}^{-3}$ и экспоненциально уменьшалась за счет диффузии при удалении от поверхности. Вследствие резкого уменьшения концентрации железа можно было рассчитывать на существенные изменения характеристик в разных областях кристаллов. Кроме того, наличие зерен в поликристаллах $\mathrm{Zn}-\mathrm{Se}$ позволяет продемонстрировать возможности двухфотонной конфокальной микроскопии для исследования макроскопических дефектов в полупроводниках. Все эксперименты проводились при комнатной температуре.

\section{Результаты}

На рис. 1 приведены „плоские“ карты люминесценции области легированного железом поликристалла $\mathrm{Zn}-\mathrm{Se}$, находящейся на расстоянии примерно $70 \mu \mathrm{m}$ от поверхности, с которой осуществлялось легирование. Исследуемая область близка к прямоугольному параллелепипеду, основанием которого является квадрат со стороной примерно $1 \mathrm{~mm}$, а высота - порядка нескольких $\mu \mathrm{m}$.

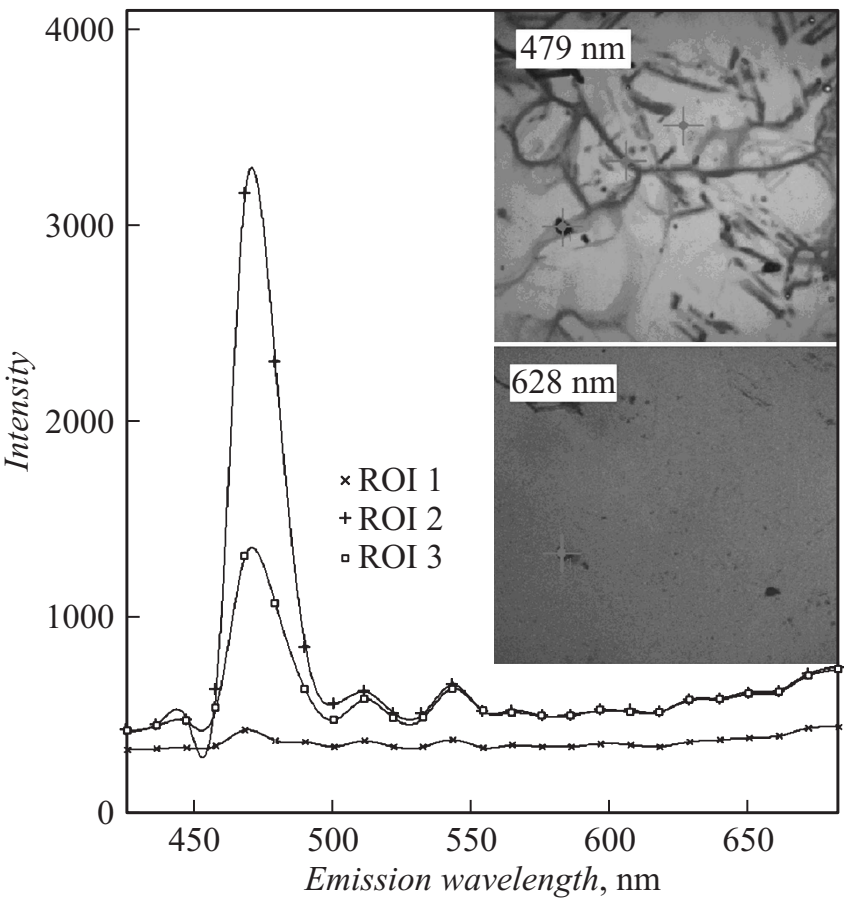

Рис. 1. „Плоские“ карты люминесценции на длинах волн 479 и $628 \mathrm{~nm}$ поли- $\mathrm{Zn}-\mathrm{Se}$, легированного железом на расстоянии $70 \mu \mathrm{m}$ от поверхности, с которой велось легирование. Спектры люминесценции трех различных областей кристалла.

Каждая картина соответствует распределению люминесценции с определенной длиной волны (на рис. $1-479$ и $628 \mathrm{~nm}$ ). Математическое обеспечение конфокального микроскопа позволяет получать спектры в любой точке снятой карты люминесценции. Спектры люминесценции различных участков исследуемой области также приведены на рис. 1. На спектре хорошо видна линия с длиной волны $0.47 \mu \mathrm{m}$, что соответствует длине волны излучения свободного экситона в $\mathrm{Zn}-\mathrm{Se}$ [8]. Наблюдаемые в более длинноволновой области линии люминесценции принадлежат примесным или структурным дефектам, или их комплексам. Видно, что интенсивности линий люминесценции резко меняются в зависимости от места расположения участка. На рис. 1 приведены карты люминесценции на длинах волн, соответствующих линиям излучения экситона и двум линиям излучения примесных или структурных дефектов. На картах, соответствующих линиям излучения экситона, отчетливо видны границы зерен. В данном случае они представляют собой области с низкой эффективностью излучательной рекомбинации. Этот результат выглядит достаточно обычным и может объясняться тем, что области границ зерен содержат много центров безызлучательной рекомбинации. В то же время на карте люминесценции, соответствующей линии спектра $628 \mathrm{~nm}$, границы зерен не выявляются, что свидетельствует о более однородном распределении центров, ответственных за люминесценцию в этой области. Данный результат иллюстрирует возможности 


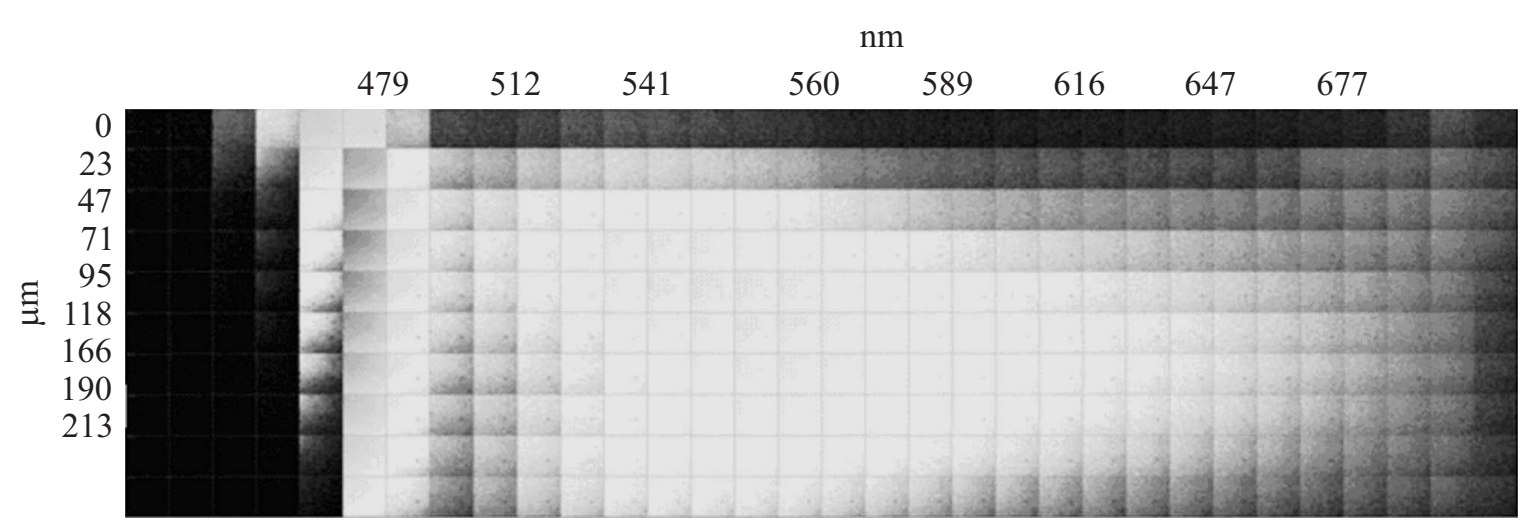

Рис. 2. „Объемная“ карта люминесценции моно-Zn-Se, легированного железом. По осям - расстояние от поверхности, с которой велось легирование и спектральный диапазон люминесценции. Более светлые области соответствуют более сильной люминесценции.

конфокальной микроскопии для исследования распределения интенсивности межзонной и примесной люминесценции в различных областях полупроводника в глубине кристалла.

На рис. 2 приведена объемная карта люминесценции „столба“ монокристалла $\mathrm{Zn}-\mathrm{Se}$. Он состоит из „плоских“ карт люминесценции аналогичных приведенным на рис. 1 областей кристалла, расположенных одна под другой на разных расстояниях от поверхности кристалла. Как и в случае рис. 1 , каждая область близка к прямоугольному параллелепипеду, имеющему в основании квадрат со стороной примерно $1 \mathrm{~mm}$ и высотой несколько $\mu \mathrm{m}$. По оси ординат отложено расстояние от поверхности кристалла, а по оси абсцисс - длина волны люминесценции, на которой снята данная карта. Легирование железом проводилось с поверхности, от которой идет отсчет расстояния. Темный цвет означает отсутствие люминесценции, более светлые области области с высокой интенсивностью люминесценции на данной длине волны, более темные - с меньшей. Видно, насколько неоднородно по кристаллу распределены примесные и структурные дефекты, выявляемые с помощью люминесценции, а также, что область, прилегающая к поверхности (до расстояний примерно 20-30 $\mu \mathrm{m}$ ), не содержит центров, излучающих на длине волны примерно $0.54 \mu \mathrm{m}$, на больших глубинах эти центры появляются. При увеличении расстояния от поверхности появляются центры, люминесцирующие с еще меньшей энергией кванта. Эти результаты демонстрируют возможности двухфотонной конфокальной микроскопии для создания объемных карт люминесценции и исследования распределения примесных и структурных дефектов в полупроводниковых кристаллах. По нашему мнению, приведенная выше информация не может быть получена с помощью обычных исследований люминесценции. При этом необходимо отметить, что снятие такой карты занимает примерно $10 \mathrm{~min}$ с установкой образца в прибор.
Безусловно, при проведении этих экспериментов надо учитывать поглощение люминесценции кристаллом. Именно с поглощением собственной люминесценции связано падение интенсивности собственной краевой люминесценции $\mathrm{Zn}-\mathrm{Se}$, коротковолновая часть которой наблюдается только в приповерхностном слое (рис. 2). Ослабление интенсивности люминесценции экситона с увеличением глубины также связано с его поглощением $\mathrm{Zn}-\mathrm{Se}$.

Остановимся теперь на возможностях данной методики для исследования структурных дефектов в полупроводниках. На рис. 1 приведены примеры, показывающие возможность выявления границ зерен в поликристалле $\mathrm{Zn}-\mathrm{Se}$. На рис. 3 показаны плоские карты люминесценции одного и того же „столбца“ поликристалла $\mathrm{Zn}-\mathrm{Se}$ на разных расстояниях от поверхности, через которую шло легирование железом, снятые на длинах волн соответствующих длине волны экситона и ,примесной“ люминесценции. Видно, что, во-первых, меняется состав примесной атмосферы вокруг границы зерен. На глубинах до $150 \mu \mathrm{m}$ они, по-видимому, содержат большое количество центров безызлучательной рекомбинации, что приводит к резкому падению интенсивности экситонной люминесценции в этой области (рис. $3, a$ ). Увеличение глубины приводит к тому, что число этих центров в этих областях уменьшается и сначала становится сопоставимым с их числом в объеме. В результате рекомбинационный контраст практически исчезает (рис. $3, c$ ). Дальнейшее увеличение расстояния от поверхности приводит к тому, что концентрация таких центров в области границ зерен становится меньше средней по объему. В результате эта область люминесцирует интенсивней, чем остальной объем кристалла. При этом центральная часть этих дефектов продолжает иметь низкую интенсивность экситонной люминесценции (рис. $3, d$ ). Центральная же зона в границах зерен, расположенных ближе к поверхности, содержит много центров, люминесцирующих в диапазоне $0.54 \mu \mathrm{m}$, что выявляется как светлая полоса в середине примесной атмосферы при снятии ,плоской“ 


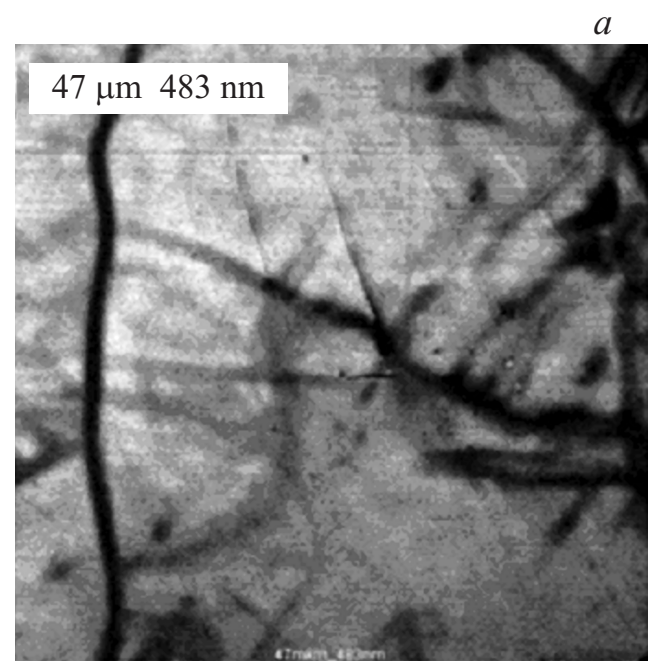

C

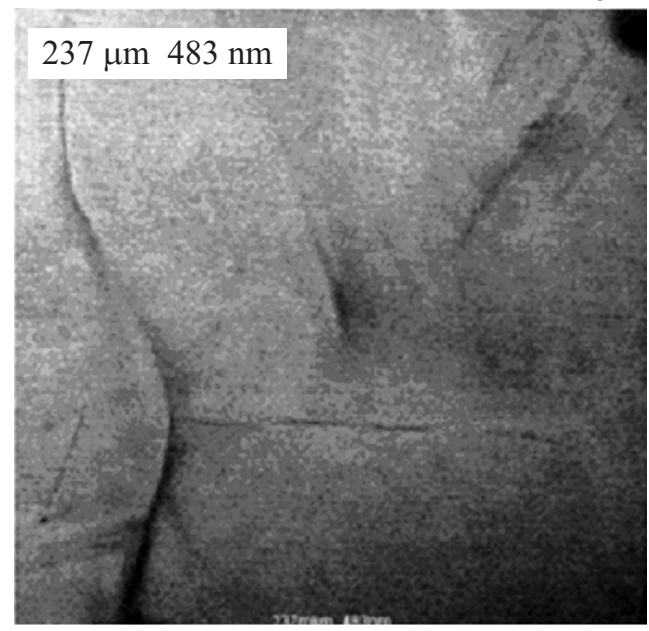

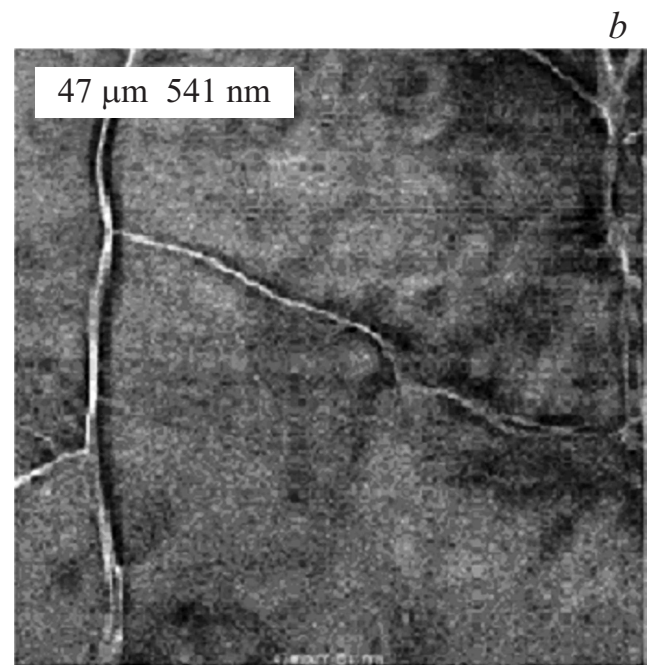

d

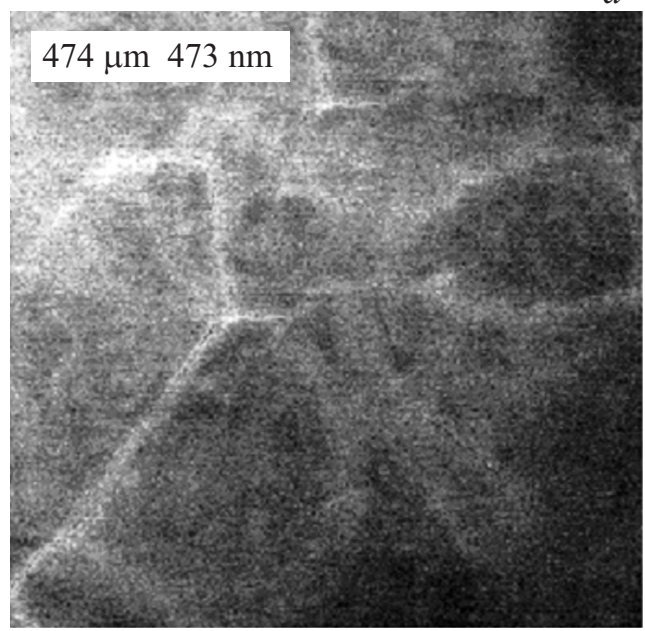

Рис. 3. „Плоские“ карты люминесценции, соответствующие разным расстояниям от поверхности, с которой велось легирование.

карты в диапазоне $0.54 \mu \mathrm{m}$ (рис. $3, b$ ). Такая информация о люминесцентных характеристиках дефектов структуры также, по-видимому, может быть получена в настоящее время только с помощью двухфотонной конфокальной микроскопии.

\section{Заключение}

Представленные результаты показывают широкие возможности двухфотонной конфокальной микроскопии для исследования объемных характеристик полупроводниковых материалов. Данная методика позволяет осуществлять экспрессную неразрушающую объемную томографию таких характеристик кристаллов, как межзонная и примесная люминесценция. Возможности этой методики могут быть существенно увеличены за счет в первую очередь расширения спектрального интервала приемной системы в ближний ИК диапазон и использования для возбуждения носителей света с большими длинами волн. Простое увеличение диапазона приемной системы до $1.5 \mu \mathrm{m}$ не только качественно увеличит возможности исследования кристаллов $\mathrm{Zn}-\mathrm{Se}$, но и позволит изучать существенно более важные в промышленном отношении материалы - GaAs, InP, CdTe, a также соединения и структуры на их основе. Сложнее обстоит дело с возможностью исследования кремния и германия в связи с их малой излучательной способностью. В такой ситуации необходимо для регистрации носителей использовать емкостные методы, например, детектора Рау [9] или измерения проводимости в СВЧдиапазоне. Существенно может повысить информативность двухфотонной конфокальной микроскопии использование холодных столов и понижение температуры образцов, например, до азотных температур. Пространственное разрешение может быть существенно улучшено (с использованием объективов с высокой апертурой), что существенно при исследовании неоднородностей в кристаллах. Необходимо также отметить, что не в полной мере использовались возможности математического обеспечения в нашей работе. 
Bсе вышесказанное позволяет утверждать, что потенциальные возможности использования современных конфокальных микроскопов для исследования объемных характеристик полупроводниковых материалов велики и могут быть существенно увеличены с помощью сравнительно несложных усовершенствований.

Данная работа выполнена в соответствии с Программой Президиума РАН „Фундаментальные основы прорывных технологий двойного назначения в интересах национальной безопасности“ (проект „Исследование возможности создания высокоэффективных лазеров ИК диапазона $(4-5 \mu \mathrm{m})$ на основе кристаллов $\mathrm{ZnSe}$, легированных железом, при ударном возбуждении ионов активатора горячими электронами“").

Авторы благодарят научного сотрудника ИОФ РАН А.В. Рябову за помощь при проведении экспериментов.

\section{Список литературы}

[1] Yuryev V.A., Kalinushkin V.P., Zayats A.V., et al. Notions and Perspectives of Nonlinear Optics. Ed. Ole Keller, Singapore; World Scientific, 1996. P. 665-670.

[2] Ищук Ю.А., Ваксман Ю.Ф., Яиун В.В. // ФТП. 2012. Т. 46. Вып. 10. С. $1288-1292$.

[3] Ищук Ю.А., Ваксман Ю.Ф., Яиун В.В. и др. // ФТП. 2011. Т. 45. Вып. 9. С. 1129-1134.

[4] Wilson T.. Confocal and Two-photon Microscopy. Wiley-Liss, 2002. P. 19-38.

[5] Diaspro A., Sheppard C. Confocal and Two-photon Microscopy. Wiley-Liss, 2002. P. 39-75.

[6] Jonkman J., Stelzer E. Confocal and Two-photon Microscopy. Wiley-Liss, 2002. P. 101-127.

[7] Noor A.S.M., Miyakwa A., Kawata Y., Torizawa M. // Appl. Phys. Lett. 2008. Vol. 92. P. 116106.

[8] Недегло Д.Д., Симашкевич А.В. Электрические и люминесцентные свойства селенида цинка. Кишинев: Штиинца, 1984. $153 \mathrm{c}$.

[9] Rau E.L., Zhukov A.N., Yakimov E.B. // Sol. Stat. Phenomena. 1998. Vol. 53-54. P. 327. 